\title{
Neuromonitoring and neuroprotection advances for aortic arch surgery
}

\author{
Matt P. Falasa, MD, ${ }^{a}$ George J. Arnaoutakis, MD, ${ }^{\mathrm{a}, \mathrm{b}}$ Greg M. Janelle, MD, ${ }^{\mathrm{c}}$ and \\ Thomas M. Beaver, MD, MPH ${ }^{\mathrm{a}, \mathrm{b}}$
}

Neurologic injury remains one of the most-feared complications of aortic arch surgery. The reported incidence of postoperative stroke after acute type A aortic dissection ranges from $8.1 \%$ to $11.5 \%{ }^{1-3}$ Even in elective totalarch replacements, the stroke rate remains $3.5 \%$ to $8.6 \%{ }^{4,5}$ At high-volume centers, excellent outcomes are possible. In a series of 114 patients undergoing elective ascending aortic replacement $(11 \%$ total arch replacement, $75 \%$ hemiarch replacement), a $<1 \%$ stroke rate was reported. ${ }^{6}$ Despite the morbidity of these complications, prospective studies on strategies to mitigate this complication are limited, with retrospective reviews and expert opinion comprising much of the available literature. Over time, hypothermic circulatory arrest (HCA) with or without cerebral perfusion, neurophysiologic intraoperative monitoring, and pharmacologic adjuncts have become the mainstays of avoiding neurologic injury during aortic arch surgery (Figure 1).

HCA in aortic arch replacement was first described by Griepp and colleagues ${ }^{7}$ in a series of 4 patients. Patients were cooled to an average esophageal temperature of $14^{\circ} \mathrm{C}$, and cerebral ischemia time was on average $43 \mathrm{mi}-$ nutes, with no neurologic injuries. HCA to varying degrees has subsequently become a mainstay of aortic arch surgery. 8,9

Strategies for improving mortality and preventing neurologic injury have evolved over time. An International Registry for Aortic Dissection study examining acute ascending aortic dissection between 1996 and 2016 demonstrated an increase in the use of antegrade cerebral perfusion (ACP) and axillary arterial perfusion and a decrease in femoral artery cannulation, with a significant decrease in-hospital mortality from $17.5 \%$ to $12.2 \%$, although neurologic outcomes were not reported. ${ }^{9}$

\footnotetext{
From the ${ }^{\mathrm{a} D e p a r t m e n t}$ of Surgery, ${ }^{\mathrm{b}}$ Division of Cardiovascular Surgery, Department of Surgery, and ${ }^{\mathrm{c} D e p a r t m e n t ~ o f ~ A n e s t h e s i o l o g y, ~ U n i v e r s i t y ~ o f ~ F l o r i d a, ~ G a i n e s v i l l e, ~}$ Fla.

Funded by the Grant and Shirle Herron Chair in Cardiovascular Surgery.

Received for publication Dec 29, 2020; accepted for publication Dec 30, 2020; available ahead of print March 24, 2021.

Address for reprints: Thomas M. Beaver, MD, MPH, Division of Cardiovascular Surgery, 1600 SW Archer Rd, Gainesville, FL 32610 (E-mail: thomas.beaver@ surgery.ufl.edu).

JTCVS Techniques 2021;7:11-9

2666-2507

Copyright (c) 2021 The Author(s). Published by Elsevier Inc. on behalf of The American Association for Thoracic Surgery. This is an open access article under the CC BY-NC-ND license (http://creativecommons.org/licenses/by-nc-nd/4.0/).

https://doi.org/10.1016/j.xjtc.2020.12.045
}

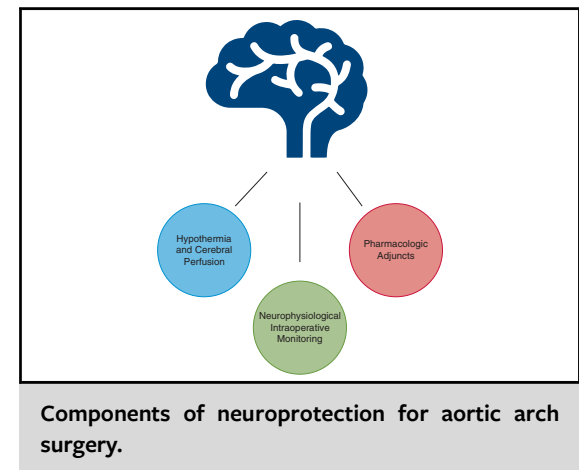

$$
\begin{aligned}
& \text { CENTRAL MESSAGE } \\
& \text { Aortic arch surgery is high risk } \\
& \text { for neurologic injury. Intraopera- } \\
& \text { tive neurologic monitoring, hy- } \\
& \text { pothermic circulatory arrest, and } \\
& \text { cerebral perfusion are critical in } \\
& \text { mitigating these injuries. }
\end{aligned}
$$$$
\text { See Commentary on page } 20 .
$$

\section{NEUROPHYSIOLOGICAL INTRAOPERATIVE MONITORING (NIOM)}

Various modalities have been implemented over the years to monitor the adequacy of HCA and cerebral perfusion. Prospective data remain limited, and there are no convincing studies comparing monitoring techniques. Cerebral oximetry by near-infrared spectroscopy (NIRS) and bispectral index (BIS), a continuous output of dualchannel electroencephalography (EEG) data processed through a proprietary algorithm, remain the most frequently used modalities.

Historically, multichannel EEG was used most frequently, but this has been widely replaced by BIS (Covidien, Boulder, Colo). ${ }^{10}$ BIS only monitors the frontal cerebral regions, in contrast to traditional multichannel EEG, and its use relies on the extrapolation that the frontal regions reflect the posterior circulation. Although BIS has not been extensively validated in the detection of cerebral ischemia, it is now frequently used and arguably more reliable to apply. ${ }^{11}$ Observational studies have demonstrated that BIS decreases to 0 at varying rates between patients with deep hypothermia. ${ }^{12}$ Because both EEG and BIS are strongly 

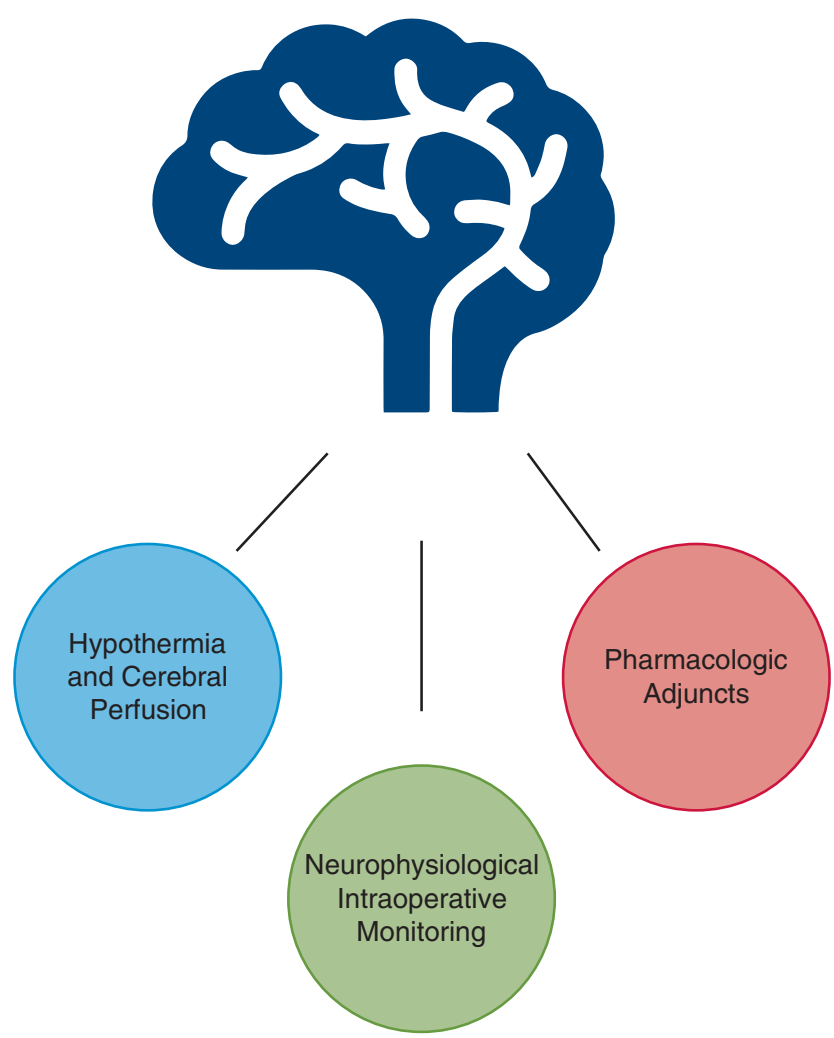

FIGURE 1. Key components of neuroprotection during surgery on the aortic arch. Hypothermia with or without cerebral perfusion, neurophysiological intraoperative monitoring, and pharmacologic adjuncts have emerged as mainstays of neurological protection during aortic arch surgery.

influenced by anesthetic agents (and are indeed used to monitor depth of anesthesia), it is important to assess the baseline readings after the induction of anesthesia and before systemic cooling. As the brain is cooled, EEG serves as a measure of cerebral metabolic activity until electrocerebral inactivity is achieved. At our center and others, a BIS reading of zero or near zero guides when deep hypothermic circulatory arrest (DHCA) can be initiated. Anesthetics are often discontinued during the cooling process to avoid EEG misinterpretation during hypothermia. ${ }^{13} \mathrm{Ba}-$ varia and colleagues ${ }^{14}$ demonstrated that most patients achieve EEG silence after 45 minutes of active cooling and that this duration (reaching nasopharyngeal temperature between $15^{\circ} \mathrm{C}$ and $20^{\circ} \mathrm{C}$ ) is generally sufficient in the absence of EEG data.

Cerebral oximetry has been widely adapted over the years. Historically, jugular bulb desaturation by invasive monitors was correlated with clinical outcomes, but logistical issues prevented the technique from becoming widespread, and the use of cerebral oximetry by NIRS has evolved as a surrogate. ${ }^{10}$ Desaturations measured by NIRS intraoperatively have been linked to postoperative neurologic injury. ${ }^{15}$ Although there are a lack of randomized data supporting its use, cerebral oximetry is widely used and is an important tool in the aortic surgery team's armamentarium, which can be used to help guide perfusion and cooling strategies.

Cerebral oximetry, as well as EEG or BIS, can help monitor cerebral perfusion in patients with aortic dissection to identify dynamic flaps or cannulas that become malpositioned intraoperatively. In addition, data obtained by NIRS, BIS, or EEG may suggest inadequate contralateral cerebral perfusion in cases performed under unilateral cerebral perfusion, as with patients lacking an intact circle of Willis. ${ }^{13}$ A study of 71 cases performed under moderate hypothermic circulatory arrest (MHCA) with ACP found that immediately after circulatory arrest, $45 \%$ of patients had an abrupt loss of electrocerebral activity, suggesting cerebral ischemia. ${ }^{16}$ This activity was restored with rapid initiation of unilateral ACP in most patients, but one required bilateral ACP to restore electrocerebral activity and another was placed back on cardiopulmonary bypass for further cooling. Although outcomes within patients in this study were equivalent, this experience highlights the need for careful NIOM when using moderate hypothermia and unilateral ACP. ${ }^{16}$

Somatosensory-evoked potentials (SEPs) are another modality that is sometimes used, but evidence for the application of this technology is limited. As with EEG, SEPs can be monitored during the cooling process to help assess when cerebral metabolic activity is suppressed, and it can also be used to localize intraoperative neurologic injury and possibly lead to corrective measures. ${ }^{13}$ Recently, a review of 224 cases using multimodal NIOM (NIRS, SEP, EEG) found good correlation between NIOM abnormalities and stroke. However, desaturation by NIRS did not correlate with stroke, suggesting NIRS assesses different pathology than EEG and SEP. ${ }^{17}$ In another institution, implementation of an acute type A aortic dissection protocol, in which all patients underwent continuous EEG and SEP monitoring, allowed for surgeons to perform immediate intraoperative adjustment of perfusion cannulas as needed; in this series, $15 \%$ of cases had intraoperative changes. In this study, neuromonitoring abnormalities prompted postoperative imaging studies and catheter-based neurointerventions when appropriate, although neither the frequency of these interventions nor the reversibility of presumed neurologic insult were discussed. Postoperative stroke rates of 3.6\% and $3.3 \%$ were seen for hemiarch and total arch replacements, respectively, which are much lower than other published studies. ${ }^{18}$

\section{HYPOTHERMIA AND CEREBRAL PERFUSION}

Hypothermia is the mainstay for cerebral protection during circulatory arrest, as it reduces metabolic demand. Stecker and colleagues ${ }^{19}$ demonstrated electroencephalogram burst-suppression in humans at nasopharyngeal temperatures of $24.4^{\circ} \mathrm{C} \pm 4^{\circ} \mathrm{C}$, with electrocerebral silence at 
$17.8^{\circ} \mathrm{C} \pm 4^{\circ} \mathrm{C}$. Deep hypothermia is commonly accepted as circulatory arrest temperatures of $14.1^{\circ} \mathrm{C}$ to $20^{\circ} \mathrm{C}$ and moderate hypothermia as $20.1^{\circ} \mathrm{C}$ to $28^{\circ} \mathrm{C}^{20}$ There is considerable variability in the site of temperature measurement, whether nasopharyngeal, rectal, or bladder measurements are used. ${ }^{19}$ Although HCA is often combined with either antegrade or retrograde cerebral perfusion, DHCA alone has been shown to be a safe approach at many centers. Ziganshin and colleagues ${ }^{21}$ reported acceptable mortality and stroke rates with DHCA as their sole cerebral protective strategy, with mean bladder temperatures of $18.7^{\circ} \mathrm{C}$ and DHCA times of up to 50 minutes. Beyond 50 minutes, the observed stroke rate climbed from $1.3 \%$ to $16.7 \%$. The maximum safe duration of DHCA when used as the sole neuroprotective strategy is contested, but rates of neurologic injury begin to climb between 25 and 60 minutes. ${ }^{22}$ The German Registry for Acute Aortic Dissection Type A (GERAADA) has subsequently corroborated this limitmortality rates began to climb when HCA alone (without any cerebral perfusion) exceeded 30 minutes. ${ }^{23}$

Two strategies have emerged for arch reconstructions requiring longer HCA times: (1) moderate hypothermic circulatory arrest with antegrade cerebral perfusion (MHCA + ACP), or (2) deep hypothermic circulatory arrest with retrograde cerebral perfusion (DHCA + RCP). Studies in animals have demonstrated superior metabolic support from ACP as compared with RCP during DHCA $\left(15^{\circ} \mathrm{C}\right) .{ }^{24}$ Under moderate HCA $\left(28^{\circ} \mathrm{C}\right)$, studies in animals demonstrated that RCP does not support cerebral metabolic demands; however, advocates of retrograde cerebral perfusion highlight that retrograde perfusion can flush out air and particulate emboli. ${ }^{25}$

A 2013 meta-analysis of 1783 patients undergoing aortic arch surgery compared DHCA alone with MHCA + ACP. This study found DHCA without any cerebral perfusion was associated with significantly more permanent neurologic deficits $(12.8 \%$ vs $7.3 \%, P=.0007)$, defined as stroke or coma. ${ }^{20}$ No differences were found in mortality or temporary neurologic deficit, and median circulatory arrest times were not analyzed in the meta-analysis but averaged 30 to 40 minutes. In general, there has been a shift toward the use of moderate HCA with ACP (often via axillary perfusion) for longer-duration cases.

The degree of hypothermia remains a point of contention, as deeper hypothermia requires longer rewarming times and is associated with acquired coagulopathy. A study of 377 patients undergoing ascending aortic repair (with or without arch repair) with ACP under moderate $\left(25^{\circ} \mathrm{C}-28^{\circ} \mathrm{C}\right)$ or deep $\left(20^{\circ} \mathrm{C}-24.9^{\circ} \mathrm{C}\right) \mathrm{HCA}$ demonstrated no difference in stroke, temporary neurologic dysfunction, or in-hospital death. ${ }^{26}$ However, lower temperature was significantly associated with reoperation for bleeding and greater markers of postoperative inflammatory response.
Adding retrograde cerebral perfusion to DHCA has shown equivalent results to ACP with MHCA. A series of 376 patients undergoing hemiarch reconstruction for nondissecting disease, with short (average 22 minutes) HCA times, compared MHCA + ACP with DHCA + RCP and found no difference in 30-day mortality or stroke. However, $\mathrm{MHCA}+\mathrm{ACP}$ was associated with shorter crossclamp and cardiopulmonary bypass times, as well as decreased transfusion requirements. ${ }^{27}$ Similarly, a review of 8169 patients undergoing elective total arch replacement compared ACP (at $24.2^{\circ} \mathrm{C}$ ) versus $\mathrm{RCP}\left(\right.$ at $21.2^{\circ} \mathrm{C}$ ) and found no difference in mortality, stroke, or transient neurologic disorder, although the use of lower temperatures with RCP was associated with longer intensive care unit length of stay. ${ }^{5}$

A recent small prospective study of 20 patients undergoing elective hemiarch replacement randomized patients to either DHCA $+\mathrm{RCP}\left(14.1^{\circ} \mathrm{C}-20^{\circ} \mathrm{C}\right)$ or $\mathrm{MHCA}+\mathrm{ACP}\left(20^{\circ} \mathrm{C}-28^{\circ} \mathrm{C}\right)$ and found no differences in crossclamp, cardiopulmonary bypass, or HCA times. Clinical outcomes including stroke, transient ischemic attack, transient neurologic dysfunction, neurologic assessment by a neurologist, and neurocognitive deficits as assessed by a computerized cognitive assessment were all equivalent. However, magnetic resonance imaging (MRI) showed ischemic lesions in $100 \%$ of patients in the MHCA + ACP group, but only $45 \%$ of the DHCA + RCP group had lesions. Notably, the MRI findings were not detected by clinical neurologic examination or neurocognitive testing. The authors suggest the increased MRI findings could be due to either manipulation and clamping of the innominate or carotid vessels during cannulation for ACP or due to fundamental differences in embolic events between ACP and RCP. ${ }^{28}$ These differences would support the use of RCP with deep HCA, but widespread adaptation for all aortic arch operations is limited by the commonly accepted notion that RCP offers less metabolic support for longer procedures, although circulatory arrest times in this study were short (19-21 minutes on average). ${ }^{5,29}$

Given the variability in patient population, disease type, circulatory arrest times, and even target temperatures between studies comparing hypothermia and perfusion strategies, relative outcomes are difficult to extrapolate to different populations, and trends must be identified from studies. DHCA alone has been demonstrated to be safe for short circulatory arrest times, but between 25 and $50 \mathrm{mi}-$ nutes, neurologic injury and mortality rates begin to climb. In general, expert opinion has favored using DHCA with RCP for intermediate duration cases due to ease of cannulation and theoretical retrograde flushing of embolic debris, while relying on either DHCA or MHCA combined with ACP for longer cases due to superior metabolic support. ${ }^{29,30}$ These neuroprotective strategies are summarized in Table 1. 
TABLE 1. Neuroprotective strategies for aortic arch surgery compared

\begin{tabular}{|c|c|c|c|}
\hline $\begin{array}{l}\text { Neuroprotection } \\
\text { strategy }\end{array}$ & $\begin{array}{l}\text { Hypothermic } \\
\text { circulatory } \\
\text { arrest time }\end{array}$ & Advantages & Disadvantages \\
\hline DHCA alone & $\begin{array}{l}\text { Short } \\
\qquad(<25-50 \mathrm{~min})\end{array}$ & $\begin{array}{l}\text { - Ease of use } \\
\text { - Equivalent outcomes for short cases }{ }^{21}\end{array}$ & $\begin{array}{l}\text { - Increased neurologic dysfunction beyond } 25 \text { - } \\
50 \mathrm{~min}^{20,22,23} \\
\text { - Increased cooling times } \\
\text { - Possibly greater reoperation rates for bleeding }\end{array}$ \\
\hline $\mathrm{DHCA}+\mathrm{RCP}$ & $\begin{array}{l}\text { Intermediate } \\
\qquad(25-50 \mathrm{~min})\end{array}$ & $\begin{array}{l}\text { - Equivalent clinical neurologic outcomes } \\
\text { - Fewer cerebral lesions detected by MRI-possible } \\
\text { retrograde flushing of debris }{ }^{28}\end{array}$ & $\begin{array}{l}\text { - Longer ICU length of stay }{ }^{5} \\
\text { - Possibly greater reoperation rates for bleeding }{ }^{26}\end{array}$ \\
\hline $\mathrm{DHCA}+\mathrm{ACP}$ & - & - Equivalent clinical neurologic outcomes ${ }^{26}$ & - Increased risk of reoperation for bleeding ${ }^{26}$ \\
\hline $\mathrm{MHCA}+\mathrm{ACP}$ & $\begin{array}{l}\text { Intermediate or } \\
\text { long }(>25 \mathrm{~min})\end{array}$ & $\begin{array}{l}\text { - Equivalent clinical neurologic outcomes }{ }^{26,27} \\
\text { - Shorter crossclamp times, transfusion } \\
\text { requirements, and bypass times }{ }^{27}\end{array}$ & $\begin{array}{l}\text { - May require bilateral ACP, based on intraoperative } \\
\text { neuromonitoring } \\
\text { - Greater incidence of cerebral lesions by } \mathrm{MRI}^{28}\end{array}$ \\
\hline
\end{tabular}

$\overline{D H C A}$, Deep hypothermic circulatory arrest; $R C P$, retrograde cerebral perfusion; $M R I$, magnetic resonance imaging; $I C U$, intensive care unit; $A C P$, antegrade cerebral perfusion; $M H C A$, moderate hypothermic circulatory arrest.

\section{FROZEN ELEPHANT TRUNK (FET)}

Patients requiring concomitant intervention on the proximal descending aorta with the FET technique are a special group of arch patients. These procedures involve off-label use of devices, as none have Food and Drug Administration approval for this application. Given the known risk for spinal cord injury, we apply this procedure selectively to patients with visceral malperfusion or true lumen compression, particularly in younger patients. A pooled analysis of 3154 patients undergoing the FET technique found a $4.7 \%$ rate of spinal cord ischemia. ${ }^{31}$ These rates are consistent with our own center's experience with FET $(4.1 \%) .{ }^{32}$ For complex distal aortic pathology, our preferred approach now is to debranch the innominate and left carotid arteries and replace the aorta to the level of the left subclavian artery (zone 2), creating a zone 0 proximal landing zone for later endovascular stent graft deployment with a left subclavian branched device or coverage of the left subclavian artery after a carotid to subclavian artery bypass. For extended coverage of the thoracic aorta, spinal cord-protective strategies may include cerebrospinal fluid drainage and monitoring of sensory- or motor-evoked potentials. $^{33}$

\section{SURGICAL TECHNIQUE AND CHOICE OF CANNULATION SITE}

There is considerable variability in cannulation techniques among centers. Overall, there has been a decrease in the use of the femoral artery over the last 20 years due to a concern for showering emboli to the brain from the descending aorta. A 2014 meta-analysis of 4476 patients sought to compare peripheral cannulation (by femoral artery) to central cannulation (defined as direct aortic, innominate, right axillary, or right subclavian artery cannulation) for initiation of cardiopulmonary bypass. There was a significant association between central cannulation and decreased in-hospital mortality, as well as decreased permanent neurologic deficit. ${ }^{34}$ Right axillary artery cannulation has emerged as the preferred technique at many centers according to a study of the International Registry of Acute Aortic Dissection. ${ }^{9}$ However, this requires a separate skin incision, and often anastomosis of a side graft, which adds additional time and risks of both bleeding and lymphocele formation.

At our center, we have favored direct aortic cannulation for most aortic arch repairs. This allows easy conversion to RCP via the SVC. In cases of acute dissection, we still favor direct aortic cannulation via Seldinger technique, ideally using epiaortic and transesophageal echo for guidance into the true lumen. We have found excellent results in elective aneurysms with brief periods of DHCA alone ( $<15$ minutes). For intermediate DHCA times (20-30 minutes), we often include retrograde cerebral perfusion. Our preferred approach for complex arch reconstruction is direct aortic cannulation, followed by arch debranching of the innominate artery and left carotid artery under DHCA, and then initiation of $\mathrm{ACP}$ via a branched graft $(14 \times 10 \times 10 \mathrm{~mm}$ or $12 \times 8 \times 8 \mathrm{~mm}$ Vascutek; Terumo Aortic, Ann Arbor, Mich). ACP is typically delivered at 8 to $10 \mathrm{~mL} / \mathrm{kg} / \mathrm{min}$ flow via a limb that is Y-configured off the cardiopulmonary bypass arterial line.

ACP may be initiated peripherally, by direct cannulation or by anastomosis of a graft side-branch, to the axillary artery or carotid artery. ${ }^{35,36}$ Alternatively, the innominate or left common carotid can be directly cannulated via an intrathoracic approach. No literature exists comparing outcomes with these different strategies, but we avoid direct cannulation of arch ostia due to concern for introducing atherosclerotic debris and air. A randomized controlled trial is 
underway comparing cerebral MRI findings in patients undergoing ACP via innominate cannulation versus right axillary cannulation. ${ }^{37}$

If axillary artery cannulation is employed with MHCA and ACP, then it is essential to monitor cerebral oximetry and arterial pressure with bilateral radial arterial monitoring lines. Anatomic studies have demonstrated that an incomplete circle of Willis may lead to inadequate perfusion of the left hemisphere in $14 \%$ to $17 \%$ of patients if the right axillary artery is used for cerebral perfusion. ${ }^{38}$ A drop in left-sided cerebral saturation can be addressed with increased cerebral perfusion or direct cannulation of the left carotid artery with a separate cannula. Alternatively, the patient can be placed back on cardiopulmonary bypass with further cooling to DHCA. ${ }^{16}$

The topic of unilateral versus bilateral ACP remains a point of contention in the literature. It has been demonstrated that cerebral perfusion gradually declines with time, and does so heterogeneously within the brain, making certain regions more susceptible to ischemia. A metanalysis of 3548 patients found low rates of neurologic injury for both DHCA + RCP and MHCA + ACP, but there were significantly longer perfusion times with bilateral cerebral perfusion, suggesting that for ACP times beyond 40 to 50 minutes, surgeons selected bilateral ACP. ${ }^{39}$ A 2017 study of 203 patients undergoing total arch replacement for type A dissection similarly found no significant difference between unilateral and bilateral ACP in terms of mortality or neurologic injury but found a nonsignificant reduction in mortality associated with bilateral ACP. ${ }^{40}$ Subsequent analysis of this study has led some authors to favor bilateral ACP, given the minimal added risk. ${ }^{3}$ A 2019 retrospective review comparing unilateral versus bilateral ACP found an association between bilateral ACP and improved overall survival within the subgroup of patients requiring ACP durations of $50 \mathrm{mi}-$ nutes or longer. ${ }^{41}$ Another 2019 retrospective review comparing the 2 techniques similarly found no significant differences in outcomes, although 5-year survival was moderately improved in the group that underwent unilateral ACP. ${ }^{42}$ These results may not be appropriately extrapolated to all patients undergoing aortic arch surgery, as there were underlying differences between the 2 groups of patients - those who underwent bilateral cerebral perfusion were more likely to undergo zone 2 or zone 3 arch replacement and had longer crossclamp times, longer circulatory arrest times, and lower hypothermic temperatures. Regardless of whether unilateral or bilateral ACP is selected, we strongly urge monitoring bilateral cerebral oximetry intraoperatively to guide adequacy of cerebral perfusion. Finally, if aortic arch debranching is performed, then the innominate can be perfused during the left carotid anastomosis, at which point bilateral perfusion can easily be initiated, limiting the duration of unilateral ACP.

\section{PHARMACOLOGIC STRATEGIES}

Prospective data demonstrating clear neuroprotective advantage from any pharmacologic agent are limited. A double-blinded, randomized controlled trial examining methylprednisolone in 7507 patients undergoing cardiopulmonary bypass for cardiac surgery failed to elicit any change in mortality or stroke. ${ }^{43}$ Steroid monotherapy, barbiturates, and mannitol were examined in a review of $2137 \mathrm{pa}-$ tients undergoing surgery for type A acute aortic dissection but failed to demonstrate any significant change in postoperative neurologic dysfunction, although mannitol has been linked to survival benefit likely due to a protective effect on the viscera. ${ }^{44}$ Thiopental was demonstrated to have a cerebral protective effect in patients with neurologic dysfunction following cardiac surgery. ${ }^{45}$ Because this short-acting barbiturate is no longer available, and longer-acting barbiturates have fallen out of favor as they impair an immediate postoperative neurologic examination, agents such as etomidate and propofol have instead been used for burst suppression and cerebral protection during DHCA. ${ }^{46}$ Some groups administer a combination of methylprednisolone, lidocaine, magnesium, and mannitol for pharmacologic neuroprotection. ${ }^{18}$

\section{CONCLUSIONS}

Surgery on the aortic arch is performed for a complex, heterogenous mix of pathologies, and evidence guiding neuroprotective strategies is lacking. For brief circulatory arrest times of less than 20 minutes, DHCA alone appears sufficient, although many centers still employ a form of cerebral perfusion. Complex arch cases requiring longer circulatory arrest times benefit from incorporating either retrograde or ACP combined with intraoperative neuromonitoring and pharmacologic adjuncts.

Our own experience favoring DHCA complemented with ACP for extended arch operations using BIS and regional cerebral oximetry reflects a stroke rate of approximately $1 \%{ }^{6}$ These results represent remarkable improvement over historical outcomes and are a testament to the efficacy of carefully employed protocol-based approaches to neuroprotection during aortic arch surgery.

\section{Conflict of Interest Statement}

The authors reported no conflicts of interest.

The Journal policy requires editors and reviewers to disclose conflicts of interest and to decline handling or reviewing manuscripts for which they may have a conflict of interest. The editors and reviewers of this article have no conflicts of interest.

\section{References}

\footnotetext{
1. Tan ME, Dossche KM, Morshuis WJ, Kelder JC, Waanders FG, Schepens MA. Is extended arch replacement for acute type A aortic dissection an additional risk factor for mortality? Ann Thorac Surg. 2003;76:1209-14.
} 
2. Tokuda Y, Miyata H, Motomura N, Oshima H, Usui A, Takamoto S. Brain protection during ascending aortic repair for Stanford type A acute aortic dissection surgery. Nationwide analysis in Japan. Circ J. 2014;78: 2431-8.

3. Pacini D, Murana G, Dimarco L, Berardi M, Mariani C, Coppola G, et al. Cerebral perfusion issues in type A aortic dissection. J Vis Surg. 2018;4: 77.

4. Preventza O, Coselli JS, Garcia A, Kashyap S, Akvan S, Simpson KH, et al. Moderate hypothermia at warmer temperatures is safe in elective proximal and total arch surgery: results in 665 patients. J Thorac Cardiovasc Surg. 2017;153: 1011-8.

5. Okita Y, Miyata H, Motomura N, Takamoto S, Japan Cardiovascular Surgery Database Organization. A study of brain protection during total arch replacement comparing antegrade cerebral perfusion versus hypothermic circulatory arrest, with or without retrograde cerebral perfusion: analysis based on the Japan Adult Cardiovascular Surgery database. J Thorac Cardiovasc Surg. 2015;149: S65-73.

6. Aalaei-Andabili SH, Martin T, Hess P, Lee T, Arnaoutakis G, Beaver TM. Even redo ascending aorta replacement has low mortality in elective setting. J Cardiovasc Surg (Torino). 2019;60:150-2.

7. Griepp RB, Stinson EB, Hollingsworth JF, Buehler D. Prosthetic replacement of the aortic arch. J Thorac Cardiovasc Surg. 1975;70:1051-63.

8. Griepp RB, Di Luozzo G. Hypothermia for aortic surgery. J Thorac Cardiovasc Surg. 2013;145:S56-8.

9. Parikh N, Trimarchi S, Gleason TG, Kamman AV, di Eusanio M, Myrmel T, et al. Changes in operative strategy for patients enrolled in the International Registry of Acute Aortic Dissection interventional cohort program. J Thorac Cardiovasc Surg. 2017; 153:S74-9.

10. Fedorow C, Grocott HP. Cerebral monitoring to optimize outcomes after cardiac surgery. Curr Opin Anaesthesiol. 2010;23:89-94.

11. Kertai MD, Whitlock EL, Avidan MS. Brain monitoring with electroencephalography and the electroencephalogram-derived bispectral index during cardiac surgery. Anesth Analg. 2012;114:533-46.

12. Hayashida M, Sekiyama H, Orii R, Chizei M, Ogawa M, Arita H, et al. Effects of deep hypothermic circulatory arrest with retrograde cerebral perfusion on electroencephalographic bispectral index and suppression ratio. J Cardiothorac Vasc Anesth. 2007;21:61-7.

13. Bergeron EJ, Mosca MS, Aftab M, Justison G, Reece TB. Neuroprotection strategies in aortic surgery. Cardiol Clin. 2017;35:453-65.

14. Bavaria J, Pochettino A, Brinster DR, Gorman RC, McGarvey ML, Gorman JL, et al. New paradigms and improved results for the surgical treatment of acute type A dissection. Ann Surg. 2001;234:336-42; discussion 342-3.

15. Zheng F, Sheinberg R, Yee MS, Ono M, Zheng Y, Hogue CW. Cerebral nearinfrared spectroscopy monitoring and neurologic outcomes in adult cardiac surgery patients: a systematic review. Anesth Analg. 2013;116:663-76.

16. Keenan JE, Wang H, Ganapathi AM, Englum BR, Kale E, Matthew JP, et al. Electroencephalography during hemiarch replacement with moderate hypothermic circulatory arrest. Ann Thorac Surg. 2016;101:631-7.

17. Ghincea CV, Anderson DA, Ikeno Y, Roda GF, Eldeiry M, Bronsert MR, et al. Utility of neuromonitoring in hypothermic circulatory arrest cases for early detection of stroke: listening through the noise. J Thorac Cardiovasc Surg. February 19, 2020 [Epub ahead of print].

18. Trivedi D, Navid F, Balzer JR, Rama J, Lacomis JM, Jovin TG, et al. Aggressive aortic arch and carotid replacement strategy for type A aortic dissection improves neurologic outcomes. Ann Thorac Surg. 2016;101:896-903; discussion 903-5.

19. Stecker MM, Cheung AT, Pochettino A, Kent GP, Patterson T, Weiss SJ, et al. Deep hypothermic circulatory arrest: I. Effects of cooling on electroencephalogram and evoked potentials. Ann Thorac Surg. 2001;71:14-21.

20. Tian DH, Wan B, Bannon PG, Misfeld M, LeMaire SA, Kazui T, et al. A metaanalysis of deep hypothermic circulatory arrest versus moderate hypothermic circulatory arrest with selective antegrade cerebral perfusion. Ann Cardiothorac Surg. 2013;2:148-58.

21. Ziganshin BA, Rajbanshi BG, Tranquilli M, Fang H, Rizzo JA, Elefteriades JA. Straight deep hypothermic circulatory arrest for cerebral protection during aortic arch surgery: safe and effective. J Thorac Cardiovasc Surg. 2014;148:888-98; discussion 898-900.

22. Gupta P, Harky A, Jahangeer S, Adams B, Bashir M. Varying evidence on deep hypothermic circulatory arrest in thoracic aortic aneurysm surgery. Tex Heart Inst J. 2018;45:70-5.
23. Boening A, Karck M, Cozelman LO, Easo J, Kruger T, Rylski B, et al. German Registry for Acute Aortic Dissection Type A: structure, results, and future perspectives. Thorac Cardiovasc Surg. 2017;65:77-84.

24. Filgueiras CL, Winsborrow B, Ye J, Scott J, Aronov A, Koslowski P, et al. A 31p-magnetic resonance study of antegrade and retrograde cerebral perfusion during aortic arch surgery in pigs. J Thorac Cardiovasc Surg. 1995;110:55-62.

25. Filgueiras CL, Ryner L, Ye J, Yang L, Ede M, Sun J, et al. Cerebral protection during moderate hypothermic circulatory arrest: histopathology and magnetic resonance spectroscopy of brain energetics and intracellular $\mathrm{pH}$ in pigs. J Thorac Cardiovasc Surg. 1996;112:1073-80.

26. Kamiya H, Hagl C, Kropivnitskaya I, Bothig D, Kallenbach K, Khaladj N, et al. The safety of moderate hypothermic lower body circulatory arrest with selective cerebral perfusion: a propensity score analysis. J Thorac Cardiovasc Surg. 2007; 133:501-9.

27. Vallabhajosyula P, Jassar AS, Menon RS, Komlo C, Gutsche J, Desai ND, et al. Moderate versus deep hypothermic circulatory arrest for elective aortic transverse hemiarch reconstruction. Ann Thorac Surg. 2015;99:1511-7.

28. Leshnower BG, Rangaraju S, Allen JW, Stringer AY, Gleason TG, Chen EP. Deep hypothermia with retrograde cerebral perfusion versus moderate hypothermia with antegrade cerebral perfusion for arch surgery. Ann Thorac Surg. 2019; 107:1104-10.

29. Griepp RB, Bonser R, Haverich A. Panel discussion: session II—aortic arch. Ann Thorac Surg. 2007;83:S824-31.

30. Ryldki B, Urbanski PP, Siepe M, Beyersdorf F, Bachet J, Gleason TG, et al. Operative techniques in patients with type A dissection complicated by cerebral malperfusion. Eur J Cardiothorac Surg. 2014;46:156-66.

31. Preventza O, Liao JL, Olive JK, Simpson K, Critsinelis AC, Price MD, et al. Neurologic complications after the frozen elephant trunk procedure: a metaanalysis of more than 3000 patients. J Thorac Cardiovasc Surg. 2020;160: 20-33.e4.

32. Alhussaini M, Abdelwahab A, Arnaoutakis GJ, Martin T, Salama Ayad MAK, Ismail AIM, et al. Neurologic outcomes in aortic arch repair with frozen elephant trunk versus 2-stage hybrid repair. Ann Thorac Surg. 2019;107:1775-81.

33. Vallabhajosyula P, Szeto WY, Desai N, Komlo C, Bavaria JE. Type II arch hybrid debranching procedure. Ann Cardiothorac Surg. 2013;2:378-86.

34. Benedetto U, Raja SG, Amrani M, Pepper JR, Zeinah M, Tonelli E, et al. The impact of arterial cannulation strategy on operative outcomes in aortic surgery: evidence from a comprehensive meta-analysis of comparative studies on 4476 patients. J Thorac Cardiovasc Surg. 2014;148:2936-43.e1-4.

35. Olsson C, Thelin S. Antegrade cerebral perfusion with a simplified technique: unilateral versus bilateral perfusion. Ann Thorac Surg. 2006;81:868-74.

36. Griepp RB, Griepp EB. Perfusion and cannulation strategies for neurological protection in aortic arch surgery. Ann Cardiothorac Surg. 2013;2:159-62.

37. Garg V, Peterson MD, Chu MW, Ouzounian M, MacArthur RG, Bozinovski J, et al. Axillary versus innominate artery cannulation for antegrade cerebral perfusion in aortic surgery: design of the Aortic Surgery Cerebral Protection Evaluation (ACE) CardioLink-3 randomised trial. BMJ Open. 2017;7:e14491.

38. Merkkola P, Tulla H, Ronkainen A, Soppi V, Oksala A, Koivisto T, et al. Incomplete circle of Willis and right axillary artery perfusion. Ann Thorac Surg. 2006; 82:74-9.

39. Malvindi PG, Scrascia G, Vitale N. Is unilateral antegrade cerebral perfusion equivalent to bilateral cerebral perfusion for patients undergoing aortic arch surgery? Interact Cardiovasc Thorac Surg. 2008;7:891-7.

40. Tong G, Zhang B, Zhou X, Tao Y, Yan T, Wang X, et al. Bilateral versus unilateral antegrade cerebral perfusion in total arch replacement for type A aortic dissection. J Thorac Cardiovasc Surg. 2017;154:767-75.

41. Angleitner P, Stelzmueller ME, Mahr S, Kaider A, Laufer G, Ehrlich M. Bilateral or unilateral antegrade cerebral perfusion during surgery for acute type A dissection. J Thorac Cardiovasc Surg. 2020;159:2159-67.e2.

42. Norton EL, Wu X, Kim KM, Patel HJ, Deeb GM, Yang B. Unilateral is comparable to bilateral antegrade cerebral perfusion in acute type A aortic dissection repair. J Thorac Cardiovasc Surg. 2020;160:617-25.e5.

43. Whitlock RP, Devereaux PJ, Teoh KH, Lamy A, Vincent J, Pogue J, et al. Methylprednisolone in patients undergoing cardiopulmonary bypass (SIRS): a randomised, double-blind, placebo-controlled trial. Lancet. 2015;386: 1243-53.

44. Krüger T, Hoffmann I, Blettner M, Borger MA, Schlensak C, Weigang E. Intraoperative neuroprotective drugs without beneficial effects? Results of the 
German Registry for Acute Aortic Dissection Type A (GERAADA). Eur J Cardiothorac Surg. 2013;44:939-46.

45. Nussmeier NA, Arlund C, Slogoff S. Neuropsychiatric complications after cardiopulmonary bypass: cerebral protection by a barbiturate. Anesthesiology. 1986;64:165-70.
46. Dorotta I, Kimball-Jones P, Applegate R II. Deep hypothermia and circulatory arrest in adults. Semin Cardiothorac Vasc Anesth. 2007;11:66-76.

Key Words: neuroprotection, aortic arch, neuromonitoring, cerebral perfusion, hypothermia 


\section{Neuroprotection for Aortic Arch Surgery: Recent Articles from AATS Journals}
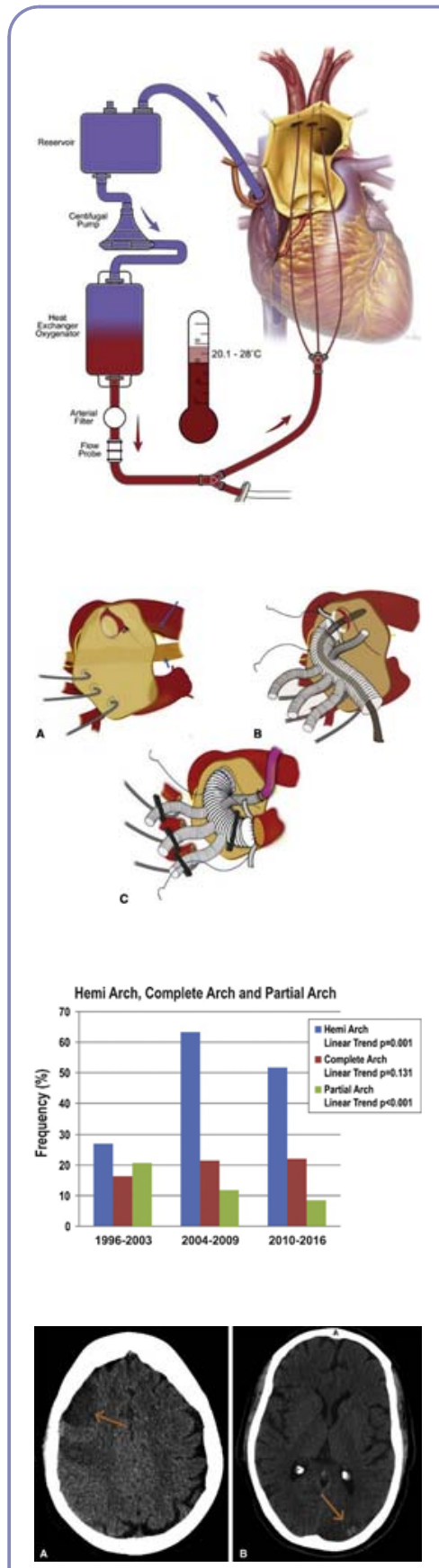

JTCVS: Moderate hypothermia at warmer temperatures is safe in elective proximal and total arch surgery: Results in 665 patients. Preventza O, Coselli JS, Garcia A, Kashyap S, Akvan S, Simpson KH, Price MD, Bakaeen FG, Cornwell LD, Omer S, de la Cruz KI, LeMaire SA, Cooley DA. J Thorac Cardiovasc Surg. 2017;153(5):1011-1018.

Commentary: When the going gets tough, the tough go colder! Girardi LN. J Thorac Cardiovasc Surg. 2017;153(5):1019-1020.

JTCVS: A study of brain protection during total arch replacement comparing antegrade cerebral perfusion versus hypothermic circulatory arrest, with or without retrograde cerebral perfusion: Analysis based on the Japan Adult Cardiovascular Surgery Database. Okita Y, Miyata H, Motomura N, Takamoto S; Japan Cardiovascular Surgery Database Organization. J Thorac Cardiovasc Surg. 2015;149(2 Suppl):S65-73. Commentary: Protecting the brain: Do we know the way? Elefteriades JA, Ziganshin BA. J Thorac Cardiovasc Surg. 2015;149(2 Suppl):S74-5.

JTCVS: Changes in operative strategy for patients enrolled in the International Registry of Acute Aortic Dissection interventional cohort program. Parikh N, Trimarchi S, Gleason TG, Kamman AV, di Eusanio M, Myrmel T, Korach A, Maniar H, Ota T, Khoynezhad A, Montgomery DG, Desai ND, Eagle KA, Nienaber CA, Isselbacher EM, Bavaria J, Sundt TM, Patel HJ. J Thorac Cardiovasc Surg. 2017;153(4):S74-S79.

Commentary: Dissecting our advances. Reardon MJ, Lumsden AB. J Thorac Cardiovasc Surg. 2017;153(4):PS80-S81.

JTCVS: Utility of neuromonitoring in hypothermic circulatory arrest cases for early detection of stroke: Listening through the noise. Ghincea CV, Anderson DA, Ikeno Y, Roda GF, Eldeiry M, Bronsert MR, Aunkst K, Fullerton DA, Reece TB, Aftab M. J Thorac Cardiovasc Surg. 2020 [In Press].

Commentary: If the news is good, it is better that we know ... if the news is bad, it is better than we know fast. Rong LQ, Weltert LP, Gaudino MFL. J Thorac Cardiovasc Surg. 2020 [In Press]. Commentary: Find first, seek later. Minatoya K. J Thorac Cardiovasc Surg. 2020 [In Press]. 

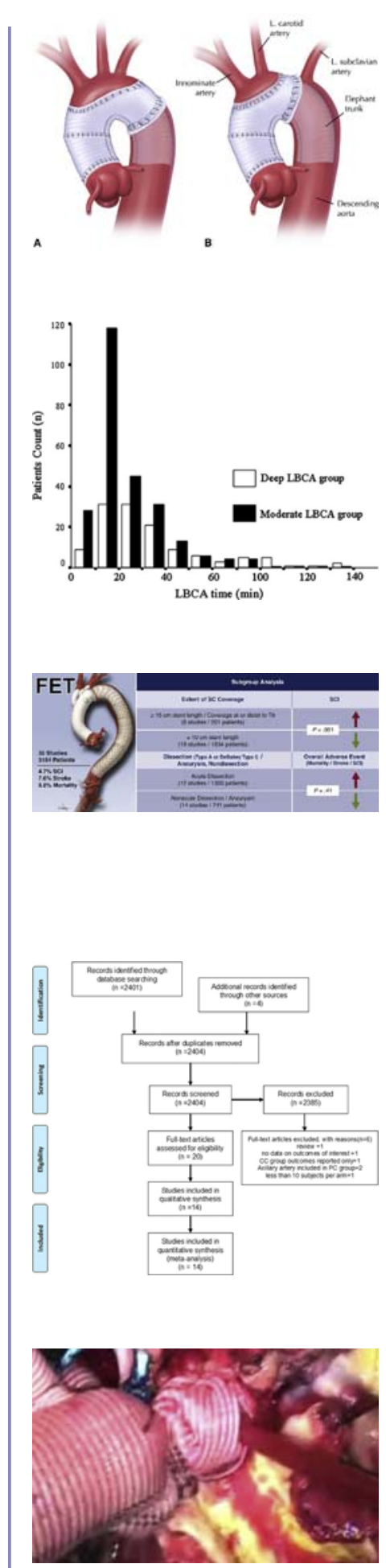

Editorial: I have only 1 brain but 2 hemispheres: Please perfuse both adequately! Bachet J. J Thorac Cardiovasc Surg. 2017;154(3):765-766.

JTCVS: Bilateral versus unilateral antegrade cerebral perfusion in total arch replacement for type A aortic dissection. Tong G, Zhang B, Zhou X, Tao Y, Yan T, Wang X, Lu H, Sun Z, Zhang W. J Thorac Cardiovasc Surg. 2017;154(3):767-775.

Commentary: Bilateral antegrade cerebral perfusion during aortic dissection surgery: If no harm, then why not? Takayama H, Borger MA. J Thorac Cardiovasc Surg. 2017;154(3):776-777. 